\title{
Case-based e-learning to improve the attitude of medical students towards occupational health, a randomised controlled trial
}

\author{
P B A Smits, ${ }^{1} \mathrm{~L}$ de Graaf, ${ }^{1} \mathrm{~K}$ Radon, ${ }^{2}$ A G de Boer, ${ }^{1}$ N R Bos, ${ }^{1} \mathrm{~F}$ J H van Dijk, \\ J H A M Verbeek ${ }^{1,3}$
}

${ }^{1}$ Coronel Institute of

Occupational Health, Academic Medical Center, University of Amsterdam, Amsterdam, The Netherlands

${ }^{2}$ Unit for Occupational and Environmental Epidemiology \& Net Teaching, Institute and Outpatient Clinic for Occupational-, Social- and Environmental Medicine, Hospital of the Ludwig-Maximilian-University, Munich, Germany

${ }^{3}$ Knowledge Transfer Team, Finnish Institute of Occupational Health, Kuopio, Finland

Correspondence to

Dr Paul Smits, Coronel Institute of Occupational Health,

Academic Medical Centre University of Amsterdam, P.O Box 22700, 1100 DE

Amsterdam, The Netherlands; p.b.smits@amc.nl

Accepted 12 September 2011 Published Online First 27 October 2011

\begin{abstract}
Objectives Undergraduate medical teaching in occupational health $(\mathrm{OH})$ is a challenge in universities around the world. Case-based e-learning with an attractive clinical context could improve the attitude of medical students towards $\mathrm{OH}$. The study question is whether case-based e-learning for medical students is more effective in improving knowledge, satisfaction and a positive attitude towards $\mathrm{OH}$ than non-case-based textbook learning.
\end{abstract}

Methods Participants, 141 second year medical students, were randomised to either case-based e-learning or text-based learning. Outcome measures were knowledge, satisfaction and attitude towards $\mathrm{OH}$, measured at baseline, directly after the intervention, after 1 week and at 3-month follow-up.

Results Of the 141 participants, 130 (92\%) completed the questionnaires at short-term follow-up and $41(29 \%)$ at 3-month follow-up. At short-term follow-up,

intervention and control groups did not show a significant difference in knowledge nor satisfaction but attitude towards $\mathrm{OH}$ was significantly more negative in the intervention group ( $F=4.041, p=0.047)$. At 3-month follow-up, there were no significant differences between intervention and control groups for knowledge, satisfaction and attitude.

Conclusions We found a significant decrease in favourable attitude during the internship in the experimental group compared with the control group. There were no significant differences in knowledge or satisfaction between case-based e-learning and textbased learning. The attitude towards $\mathrm{OH}$ should be further investigated as an outcome of educational programmes.

\section{INTRODUCTION}

Undergraduate medical teaching in occupational health $(\mathrm{OH})$ is a challenge in many universities around the world. ${ }^{1-4}$ A future career as an $\mathrm{OH}$ physician is not popular among medical students. Some of the reasons for this attitude are that $\mathrm{OH}$ is considered to be far apart from clinical practice, that it involves many administrative tasks and that it does not appeal to the diagnostic and other core skills of physicians. ${ }^{5}{ }^{6}$ Various formats of $\mathrm{OH}$ teaching programmes have been introduced to improve teaching and to tailor programmes to students' perceived learning needs and preferences. ${ }^{1-3} 7$ Students especially rated case scenarios

\section{What this paper adds}

- Occupational health is not a very popular medical specialism among medical students.

- Various educational formats have been tried to improve the knowledge of medical students and their attitude towards occupational health but little is known about their efficacy.

- In our study, case-based e-learning did not improve the attitude of second year medical students towards occupational health when compared with non-case-based textbook learning.

- Attitude towards occupational health is a valuable outcome measure in addition to the more common learning outcome measures knowledge, skills and performance.

or case-based learning as helpful in general and more helpful than workplace visits. ${ }^{2} 8$

Evidence is available that internet-based learning has large effects on knowledge outcomes, skills and learner's behaviour when compared with no intervention but similar effects when it is compared with non-internet instructional methods. ${ }^{9}$ Raupach et $a l^{10}$ reported virtual collaborative learning to be as effective as problem-based learning sessions in the acquisition of reasoning skills in fourth year medical students. However, e-learning could increase the interest of medical students by maximising the use of clinical relevance. ${ }^{11}$ We hypothesised that presenting cases would thus favourably influence students' attitude towards $\mathrm{OH}$.

Evidence about students' satisfaction with e-learning is contradictory. In the meta-analysis of Cook et al, ${ }^{9}$ internet-based learning had no significant effect on satisfaction compared with noninternet formats. Carroll et al ${ }^{12}$ stated that the use of real-world cases are well perceived by doctors in the UK. On the other hand, Raupach reported webbased learning to be less acceptable than traditional problem-based learning in fourth year medical students. Burgess et al ${ }^{13}$ stated that postgraduate students prefer core-teaching material to remain in the printing medium with online practical exercises as supplement.

Knowledge, skills and satisfaction are regular outcome measures in medical education research. ${ }^{14}$ 
The effect of education on the attitude and views of medical students towards a specific medical content or profession is less well studied. Attitude towards $\mathrm{OH}$ represents views, perceptions and preconceived opinions of students about $\mathrm{OH}$ and $\mathrm{OH}$ physicians. ${ }^{15}$ A positive attitude may reinforce the learning efforts of the students, which is vital in the learning process. ${ }^{16}$

Therefore, case-based e-learning, with an attractive and relevant clinical context, might be a means to stimulate the interest of medical students in $\mathrm{OH}$ and thus to improve their rather negative attitude towards the specialty of $\mathrm{OH}$ and a future career as an $\mathrm{OH}$ physician.

Therefore, the research question of this study is: Is case-based e-learning compared with traditional text-based learning more effective in improving knowledge, satisfaction or a positive attitude towards $\mathrm{OH}$ in second year medical students than non case-based textbook learning?

\section{METHODS \\ Study design}

In 2008 and 2009, we conducted a randomised controlled trial.

\section{Participants}

Participants were second year medical students at the Academic Medical Center in Amsterdam, the Netherlands, who received their first formal education about $\mathrm{OH}$ during their medical studies.

\section{Intervention and control groups}

Students were randomly assigned to an intervention group and a control group by means of a random number table created in Excel that was matched to a list of students that were registered for the course. The even numbers were assigned to the intervention group.

After a short introduction about the research project, the group was split up in the intervention and the control groups. All students in the intervention group elaborated three occupational medicine e-learning cases on individual computers. The topics of the e-learning cases were maternity protection, hepatitis $B$ in a medical student and occupational asthma. These cases are designed by the NeTWoRM group (Netbased Training for Work-Related Medicine) and suitable for medical students. ${ }^{7}$ The control group received written material about the same topics, which they could read. This written material consisted of photocopies of pages of an Occupational Medicine textbook, practice guideline material and scientific articles. The number of pages was adjusted to the available time.

For both groups, learning was scheduled for half a day and formed the start of a junior internship of 1 week. All students worked in a classroom without further guidance or control. In addition to learning about occupational diseases, the objective of the internship was to learn the basics of occupational history taking and to get to know $\mathrm{OH}$ practice through 3 days of actual practice visits with an occupational physician. The students knew that they would be tested, but they knew also that there were no pass/fail criteria.

\section{Measures}

We used three different measures to evaluate the outcome of the educational process: a questionnaire about attitude towards $\mathrm{OH}$, one about knowledge of $\mathrm{OH}$ and one about satisfaction. The participants completed the questionnaires at the start of day 1 as baseline measurement, directly after the total intervention, at the end of the junior internship at day 5 and after 3-month follow-up.
The attitude part consisted of 15 questions. To answer the questions a 5-point Likert scale was used with anchors ranging from disagree to agree. The total questionnaire thus could yield a minimum score of 15 and a maximum score of 75 , with 75 indicating a maximal positive attitude. Knowledge consisted of 20 questions, divided in multiple-choice, open-ended and true/ false questions. The scores are presented as percentages of correctly answered questions. Satisfaction was measured with nine questions: one was a general rating for satisfaction (range $1-10)$, five questions about satisfaction with the course content (5-point Likert scale, minimum score 5, maximum 25) and three questions about satisfaction with learning (5-point Likert scale, minimum score 3, maximum 15).

To prevent recall bias, we developed three different but comparable versions of the attitude and knowledge questionnaires. Participants received these different versions in random order at the first three measurement moments so that in the end each participant had answered all three versions. The use of these questionnaires was balanced within both groups. The same satisfaction questionnaire was used at the three follow-up times. For the measurement after 3-month follow-up, all participants received the same questionnaire.

\section{Statistical analyses}

The data were entered into a database without the researcher knowing to which group the participant belonged. Data were analysed using Statistical Package for Social Sciences (SPSS) V.16. Checking the three versions of the questionnaires with one-way analysis of variance revealed that one version of the knowledge questionnaire had lower scores than the other versions. We calculated the effect of the intervention on knowledge by calculating the mean percentage or mean number of correct answers per questionnaire. Next, we used the general linear model for repeated measures to test if there were effects of time, group and an interaction of time and group on the mean percentage or mean number of correct answers. To adjust for differences in the knowledge questionnaire versions, we included the baseline scores of knowledge as covariates in the analyses. We used Mauchly's Test of Sphericity to test for sphericity. If Mauchly's test was significantly different, the assumption of sphericity was rejected and the corrected Greenhouse-Geisser value was utilised. For attitude, we summed up all items that indicated an attitude favourable towards $\mathrm{OH}$ and we followed the same analytical procedure as for the knowledge test. For the three questions where the statement implicated a negative attitude towards occupational medicine, we reversed the score so that the total score indicates a total favourable attitude towards occupational medicine.

To make up for missing values, we used imputation by carrying forward the last observation to the measurement of the junior internship week. We checked if the responders at day 5 were different from the non-responders, which they were not. Therefore, we assumed that the missing values were not systematically different and could be imputed by the last observation carried forward. We decided that there were too many missing values at the follow-up measurement 3 months after the junior internship week to make a reasonable estimation, so no imputation was done for this measurement. A $p$ value $<0.05$ is taken as cut-off value for statistical significance.

\section{RESULTS}

There were 141 students who were eligible, and all could be randomised to the intervention or the control group and 128 
completed all questionnaires at baseline. One hundred and thirty students $(92 \%)$ completed the questionnaires at the end of the educational programme on day 1: 64 in the intervention group and 66 in the control group. At the end of day 5, 124 students completed the questionnaires: 61 in the intervention group and 63 in the control group. It was more difficult to get questionnaires back at 3-month follow-up. Only 41 students (29\%) completed all four questionnaires: 18 in the intervention group and 23 in the control group.

The baseline characteristics of the students are described in table 1. There were no significant or relevant differences in age or gender between the intervention and the control groups at baseline. About the characteristics of the group that responded at follow-up (3 months), there were no significant differences between responders $(n=41)$ and non-responders $(n=100)$ at follow-up regarding age, sex and attitude score at baseline. Knowledge score differed significantly at baseline between responders and non-responders $(p=0.011)$, with responders having a higher score.

At the first three measurement times, significant time effects were present for attitude $(\mathrm{F}=8.9, \mathrm{p}=0.001)$ decreasing over time and for satisfaction increasing over time (general satisfaction $\mathrm{F}=5.3 \quad(\mathrm{p}=0.023)$; content satisfaction $\mathrm{F}=59.6 \quad(\mathrm{p}<0.001)$; learning satisfaction $\mathrm{F}=8.3(\mathrm{p}=0.005))$. There was also a significant interaction effect of time and group for attitude $(\mathrm{F}=4.0$, $p=0.047$ ), meaning that there was a significant decrease of attitude in the intervention group compared with the control group. In table 2 , the crude mean scores of the two groups are shown at follow-up directly after the intervention and at day 5 at the end of the course.

There were no significant interaction effects of time and group for knowledge $(\mathrm{F}=0.7 ; \mathrm{p}=0.42)$ and satisfaction (general satisfaction $F=0.01 \quad(p=0.94)$; content satisfaction $F=0.03$ $(p=0.86)$; learning satisfaction $F=0.3(p=0.58)$ ), meaning that there were no significant differences between both groups at any of these measurement times for knowledge and satisfaction.

For the group of 41 participants that completed the questionnaires after 3-month follow-up (table 3), there were no significant interaction effects between group and time meaning that there were no differences between intervention and control groups in outcome at the four measurement times. In table 3, the mean scores at all measurement times are shown for the subgroup that could be followed for 3 months.

\section{DISCUSSION}

We compared the effects of case-based e-learning as a standalone option, offered in the classroom in a second year $\mathrm{OH}$ junior internship, to text-based learning under similar conditions. There was a significant decrease in favourable attitude during the internship in the experimental group compared with the control group immediately after the internship. There were no significant differences between experimental and control group for knowledge and satisfaction at any point of follow-up.

Table 1 Baseline characteristics of participants $(N=141)$

\begin{tabular}{lcc}
\hline Characteristics & Intervention & Control \\
\hline Age in years, mean $(\mathrm{SD})\left(\mathrm{N}_{\mathrm{i}}=71, \mathrm{~N}_{\mathrm{c}}=70\right)$ & $21(1.7)$ & $21(1.9)$ \\
Women, $\mathrm{n}(\%)\left(\mathrm{N}_{\mathrm{i}}=71, \mathrm{~N}_{\mathrm{c}}=70\right)$ & $49(69.0)$ & $51(72.9)$ \\
Mean attitude at baseline $(\mathrm{SD})\left(\mathrm{N}_{\mathrm{i}}=63, \mathrm{~N}_{\mathrm{c}}=64\right)$ & $49.8(5.2)$ & $51.1(5.3)$ \\
Mean \% knowledge at baseline $(\mathrm{SD})\left(\mathrm{N}_{\mathrm{i}}=64, \mathrm{~N}_{\mathrm{c}}=64\right)$ & $52.4(10.2)$ & $53.1(9.9)$ \\
\hline $\mathrm{N}_{\mathrm{c}}$, number of participants in the control group; $\mathrm{N}_{\mathrm{i}}$, number of participants in the intervention \\
group.
\end{tabular}

Table 2 Total scores of the intervention and control groups directly after the intervention and at day 5

\begin{tabular}{|c|c|c|}
\hline \multirow[b]{2}{*}{ Topic } & \multicolumn{2}{|c|}{ Mean total scores (SD) } \\
\hline & Intervention & Control \\
\hline \multicolumn{3}{|c|}{ Attitude $\left(\mathrm{N}_{\mathrm{i}}=63, \mathrm{~N}_{\mathrm{c}}=64\right)$, maximum score 75} \\
\hline Directly after the intervention & $49.0(5.9)$ & $50.5(4.4)$ \\
\hline At day 5 & $47.1(8.4)$ & $49.4(5.8)^{*}$ \\
\hline \multicolumn{3}{|c|}{ Knowledge $\left(\mathrm{N}_{\mathrm{i}}=64, \mathrm{~N}_{\mathrm{c}}=64\right)$, maximum score $100 \%$} \\
\hline Directly after the intervention & $53.4(10.4)$ & $54.6(10.0)$ \\
\hline At day 5 & $53.1(9.1)$ & $54.2(8.1) \dagger$ \\
\hline \multicolumn{3}{|c|}{ Satisfaction general rating $\left(\mathrm{N}_{\mathrm{i}}=64, \mathrm{~N}_{\mathrm{c}}=66\right)$, maximum score 10} \\
\hline Directly after the intervention & $6.2(1.2)$ & $6.3(1.2)$ \\
\hline At day 5 & $6.5(1.0)$ & $6.5(1.3) \neq$ \\
\hline \multicolumn{3}{|c|}{ Satisfaction with course content $\left(\mathrm{N}_{\mathrm{i}}=63, \mathrm{~N}_{\mathrm{c}}=63\right)$, maximum score 25} \\
\hline Directly after the intervention & $16.7(2.9)$ & $16.8(2.5)$ \\
\hline At day 5 & $18.9(2.3)$ & $18.7(2.4) \S$ \\
\hline \multicolumn{3}{|c|}{ Satisfaction about learning $\left(\mathrm{N}_{\mathrm{i}}=63, \mathrm{~N}_{\mathrm{c}}=63\right)$, maximum score 15} \\
\hline Directly after the intervention & $9.5(2.3)$ & $9.7(2.0)$ \\
\hline At day 5 & $10.1(2.2)$ & $10.2(2.2)$ \\
\hline
\end{tabular}

${ }^{*}$ Repeated measures interaction time and group: $F=4.0, p=0.047$.

†Repeated measures interaction time and group: $F=0.7, p=0.42$.

†Repeated measures interaction time and group: $F=0.01, p=0.94$

§Repeated measures interaction time and group: $F=0.03, p=0.86$.

9Repeated measures interaction time and group: $F=0.3, p=0.58$.

$\mathrm{N}_{\mathrm{c}}$, number of participants in the control group; $\mathrm{N}_{\mathrm{i}}$, number of participants in the intervention group.

One of the strengths of our study is the randomised controlled design. Thus, we could prevent selection bias in the sense that students who are more attracted to one of the teaching methods would have a possibility to influence this choice. Another strong point is that, to our knowledge, this is the first study that used attitude towards $\mathrm{OH}$ as an outcome measure in addition to the more common learning outcome measures knowledge, skills and performance.

A limitation of the study is that this was a rather short, one morning only, educational programme, and the effect of the programme should not be overestimated. In addition, the educational programme was embedded in a longer junior internship that could have had a more powerful effect on attitude at longer follow-up. If there would have been an effect of case-based e-learning, this should have been apparent immediately after the first educational session at day 1 . Unfortunately, we could only measure the outcome at longer term in a small subsample of students. Despite repeatedly requests by mail, we were not able to increase the response. Students were apparently busy with other assignments in their study and not motivated to complete our questionnaires. It is clear that the outcomes in this subsample can be biased by the attrition of participants. These results should therefore be interpreted with great caution. Another limitation is that the questionnaire with which we measured attitude towards $\mathrm{OH}$ had only face validity and we cannot say which differences are meaningful in a practical sense. In advance, we did not expect differences in knowledge. But we did expect a positive effect on satisfaction and attitude and that the sample size would be sufficient to detect such a difference.

In this study, we found a significant short-term negative effect of the intervention on the attitude towards $\mathrm{OH}$ at the measurement at the end of the $\mathrm{OH}$ junior internship week. The differences are small, and the question is whether this difference between the e-learning group and the text-based group is relevant. The decrease of attitude towards $\mathrm{OH}$ is apparent directly after the intervention. The junior internship does not change this development. Intriguing is the decrease of the attitude scores for both groups during the junior internship. An 
Table 3 Total scores of the intervention and control groups at baseline, directly after intervention, at day 5 and after 3 months

\begin{tabular}{|c|c|c|}
\hline \multirow[b]{2}{*}{ Topic } & \multicolumn{2}{|c|}{ Mean total scores (SD) } \\
\hline & Intervention & Control \\
\hline \multicolumn{3}{|c|}{ Attitude $\left(\mathrm{N}_{\mathrm{i}}=17, \mathrm{~N}_{\mathrm{c}}=23\right)$, maximum score 75} \\
\hline At baseline & $50.1(5.0)$ & $52.2(4.6)$ \\
\hline Directly after the intervention & $49.8(5.8)$ & $51.0(5.0)$ \\
\hline At day 5 & $48.8(6.7)$ & $50.3(5.1)$ \\
\hline After 3-month follow-up & $46.9(5.3)$ & $45.5(8.3)^{*}$ \\
\hline \multicolumn{3}{|c|}{ Knowledge $\left(\mathrm{N}_{\mathrm{i}}=18, \mathrm{~N}_{\mathrm{c}}=23\right)$, maximum score $100 \%$} \\
\hline At baseline & $56.7(11.2)$ & $54.3(10.0)$ \\
\hline Directly after the intervention & $52.8(9.4)$ & $56.2(11.1)$ \\
\hline At day 5 & $52.6(8.2)$ & $55.8(6.9)$ \\
\hline After 3-month follow-up (T3) & $50.0(8.4)$ & $49.1(9.8) \dagger$ \\
\hline \multicolumn{3}{|c|}{ Satisfaction general rating $\left(\mathrm{N}_{\mathrm{i}}=17, \mathrm{~N}_{\mathrm{c}}=22\right)$, maximum score 10} \\
\hline At baseline & NA & NA \\
\hline Directly after the intervention & $6.6(1.3)$ & $6.1(1.0)$ \\
\hline At day 5 & $6.4(1.2)$ & $6.2(1.3)$ \\
\hline After 3-month follow-up & $6.5(1.4)$ & $6.2(0.8) \ddagger$ \\
\hline \multicolumn{3}{|c|}{ Satisfaction with course content $\left(\mathrm{N}_{\mathrm{i}}=18, \mathrm{~N}_{\mathrm{c}}=23\right)$, maximum score 25} \\
\hline At baseline & NA & NA \\
\hline Directly after the intervention & $16.3(3.4)$ & $16.8(2.6)$ \\
\hline At day 5 & $19.2(2.8)$ & $18.7(2.3)$ \\
\hline After 3-month follow-up & $17.7(3.1)$ & $18.7(3.5) \S$ \\
\hline \multicolumn{3}{|c|}{ Satisfaction about learning $\left(\mathrm{N}_{\mathrm{i}}=18, \mathrm{~N}_{\mathrm{c}}=23\right)$, maximum score 15} \\
\hline At baseline & NA & NA \\
\hline Directly after the intervention & $9.7(2.7)$ & $9.4(2.1)$ \\
\hline At day 5 & $9.8(2.6)$ & $10.4(2.4)$ \\
\hline After 3-month follow-up & $9.7(2.5)$ & $9.6(2.2) \uparrow$ \\
\hline
\end{tabular}

*Repeated measures interaction time and group: $\mathrm{F}=2.7, \mathrm{p}=0.107$.

†Repeated measures interaction time and group: $F=0.13, p=0.722$

$\neq$ Repeated measures interaction time and group: $F=5.8, p=0.451$.

§Repeated measures interaction time and group: $F=2.2, p=0.146$.

TRepeated measures interaction time and group: $F=0.18, p=0.673$

$\mathrm{NA}$, not applicable; $\mathrm{N}_{\mathrm{c}}$, number of participants in the control group; $\mathrm{N}_{\mathrm{i}}$, number of

participants in the intervention group.

explanation for this could be that second year students are rather naive towards $\mathrm{OH}$ and that the students are focused on clinical problems and clinical specialties in a hospital setting. ${ }^{5} 6$ After the educational programme and the occupational medicine internship, they have learnt that occupational medicine is different from clinical specialties and therefore they develop a less favourable attitude towards occupational medicine. And maybe the students expected to be exposed to more cases in the internship, after receiving some elaborated cases at the start? Another consideration is that the attitudes of medical students towards various specialties change during the study. Students could be more open towards a non-clinical specialty, and an educational programme on occupational medicine could thus be more effective in a later stage of the study when students have a more varied clinical experience. At that stage, occupational medicine could become a medical field of their choice.

Our results are similar to those of Diachun et $a l^{17}$ who studied the effect of education in geriatrics. They report a 'worsened attitude' of students towards older adults after a geriatric clerkship and conclude that this might be because geriatrics is regarded as a non-essential discipline in medical education. A comparable conclusion is drawn for Canadian students' perceptions of public health. ${ }^{18}$

This study found that an e-learning format resulted in similar changes in knowledge and satisfaction as a non-internet-based text-based learning format in medical students. ${ }^{9}$ We offered the e-learning in the classroom, and therefore, we did not make use of one of the advantages of e-learning which is that it can be implemented independent of time and place. It has been argued that a blended approach, combining e-learning formats with other face-to-face formats, is more effective than e-learning as a stand-alone option. ${ }^{19}$ In addition, a strong educational context, and 'exam-relevance of the e-learning content', has been advocated. ${ }^{20}$ In future research, it should be studied if internet-based formats work better under these conditions. ${ }^{9} 21$ The attitude towards $\mathrm{OH}$ should be further investigated as an outcome of educational programmes.

Funding This study was supported by EU Lifelong Learning, NeTWoRM project.

\section{Competing interests None.}

Contributors PBAS is the guarantor for this article and the other authors have contributed to the analysis and commented on the drafts of the manuscript.

Provenance and peer review Not commissioned; externally peer reviewed.

\section{REFERENCES}

1. Braeckman L, Bekaert M, Cobbaut $L$, et al. Workplace visits versus case studies in undergraduate occupational medicine teaching. J Occup Environ Med 2009;51:1455-9.

2. Grime $\mathbf{P}$, Williams S, Nicholson S. Medical students' evaluation of a teaching session in occupational medicine: the value of a workplace visit. Occup Med 2006; 56:110-14

3. Kolb S, Wengenroth L, Hege I, et al. Case based e-learning in occupationa medicine-a European approach. J Occup Environ Med 2009;51:647-53.

4. Donnelly AB, Agius RM. The distance learning courses in occupational medicine. 20 years and onwards. Occup Med 2005;55:319-23.

5. Soethout MB, Ten Cate OJ, van der Wal G. Development of interest in a career in public health during medical school. Public Health 2008;122:361-6.

6. Lefevre $\mathbf{J H}$, Roupret $\mathrm{M}$, Kerneis $\mathrm{S}$, et al. Career choices of medical students: a national survey of 1780 students. Med Educ 2010;44:603-12.

7. Kolb S, Reichert J, Hege I, et al. European dissemination of a web- and case-based learning system for occupational medicine: NetWoRM Europe. Int Arch Occup Environ Health 2007:80:553-7.

8. Radon K, Kolb S, Reichert J, et al. Case-based e-learning in occupationa medicine-The Networm Project in Germany. Ann Agric Environ Med 2006;13:93-8.

9. Cook DA, Levinson AJ, Garside $S$, et al. Internet-based learning in the health professions: a meta-analysis. JAMA 2008;300:1181-96.

10. Raupach T, Muenscher $C$, Anders $S$, et al. Web-based collaborative training of clinical reasoning: a randomized trial. Med Teach 2009;31:e431-7.

11. Svirko E, Mellanby J. Attitudes to e-learning, learning style and achievement in learning neuroanatomy by medical students. Med Teach 2008;30:e219-27.

12. Carroll C, Booth A, Papaioannou D, et al. UK health-care professionals' experience of on-line learning techniques: a systematic review of qualitative data. J Contin Educ Health Prof 2009;29:235-41.

13. Burgess G, Holt A, Agius R. Preference of distance learning methods among post-graduate occupational physicians and hygienists. Occup Med 2005;55: 312-18

14. Cohen Schotanus J. Kwaliteit van (medisch) onderwijs [Quality of (medical) education]. Tijdschr Med Onderwijs. (Dutch J Med Educ) 2007:26:109-10.

15. Franco G. Students' perception of occupational medicine. J Occup Environ Med 1996:38:240-1.

16. ten Cate $\mathbf{0}$. What happens to the student? The neglected variable in educational outcome research. Adv Health Sci Educ Theory Pract 2001;6:81-8.

17. Diachun L, Van Bussel L, Hansen KT, et al. 'But I see old people everywhere': dispelling the myth that eldercare is learned in nongeriatric clerkships. Acad Med 2010;85:1221-8

18. Tyler IV, Hau M, Buxton JA, et al. Canadian medical students' perceptions of public health education in the undergraduate medical curriculum. Acad Med 2009;84:1307-12.

19. Childs S, Blenkinsopp E, Hall A, et al. Effective e-learning for health professionals and students-barriers and their solutions. A systematic review of the literature-findings from the HeXL project. Health Info Libr J 2005;(22 Supp 2):20-32.

20. Hege I, Ropp V, Adler M, et al. Experiences with different integration strategies of case-based e-learning. Med Teach 2007;29:791-7.

21. Cook DA. The research we still are not doing: an agenda for the study of computerbased learning. Acad Med 2005;80:541-8. 


\section{Case-based e-learning to improve the attitude of medical students towards occupational health, a randomised controlled trial}

P B A Smits, L de Graaf, K Radon, A G de Boer, N R Bos, F J H van Dijk and $\mathrm{J} \mathrm{H}$ A M Verbeek

Occup Environ Med 2012 69: 280-283 originally published online October 27,2011

doi: 10.1136/oemed-2011-100317

Updated information and services can be found at:

http://oem.bmj.com/content/69/4/280

\section{These include:}

References This article cites 20 articles, 3 of which you can access for free at: http://oem.bmj.com/content/69/4/280\#BIBL

Email alerting Receive free email alerts when new articles cite this article. Sign up in the service box at the top right corner of the online article.

\section{Notes}

To request permissions go to:

http://group.bmj.com/group/rights-licensing/permissions

To order reprints go to:

http://journals.bmj.com/cgi/reprintform

To subscribe to BMJ go to:

http://group.bmj.com/subscribe/ 